\title{
Direito de Propriedade e Teoria da Justiça: a defesa da propriedade na justiça distributiva a partir da concepção de John Rawls
}

\author{
Property Rights and Theory of Justice: the defense of property in distributive \\ justice from the conception of John Rawls
}

\author{
João Daniel Macedo de Sá ${ }^{1}$ \\ ${ }^{1}$ Universidade Federal do Pará, Belém, PA, Brasil
}

\begin{abstract}
Resumo: O presente artigo aborda o tema do direito de propriedade a partir da teoria da justiça de John Rawls. O objetivo é analisar em que medida a concepção de justiça de Rawls aceita a defesa da propriedade privada individual. Para alcançar tal objetivo, inicialmente apresenta-se os contornos do conceito de propriedade e discute-se a compreensão da propriedade no contexto da justiça distributiva. Por fim, analisa-se a defesa da propriedade a partir da concepção de justiça proposta por Rawls. Pretende-se demonstrar que o direito de propriedade é uma liberdade substantiva, em determinado grau e amplitude invioláveis e indisponíveis, e que, apesar de Rawls não considerar que o direito à propriedade da terra mereça ser protegido pelo primeiro princípio, sua formulação permite que referido direito possa ser protegido como uma liberdade básica, em complemento com o segundo princípio, na medida em que possibilite a redução das desigualdades sociais e econômicas e o aumento da igualdade de oportunidades.
\end{abstract}

Palavras-chave: Direito de Propriedade. Terra. Teoria da Justiça. John Rawls.

\begin{abstract}
This article addresses the property right theme from John Rawls theory of justice. The objective is to analyze to what extent Rawls conception of justice accepts the defense of individual private property. In order to reach this objective, we first present the contours of the concept of property and discuss the understanding of property in the context of distributive justice. Finally, we analyze the defense of property from the conception of justice proposed by Rawls. It is intended to demonstrate that the right of property is a substantive liberty, to a certain degree and extent inviolable and unavailable, and that although Rawls does not consider that the right to property of the land deserves to be protected by the first principle, its formulation allows that right to be protected as a basic liberty, in addition to the second principle, to the extent that it enables the reduction of social and economic inequalities and the increasing of equal opportunities.
\end{abstract}

Keywords: Property Right. Land. Theory of Justice. John Rawls.

Recebido em: 25/05/2018

Revisado em: 12/02/2019

Aprovado em: 22/07/2019 


\section{Introdução: contornos do conceito de propriedade}

O objetivo do presente trabalho é analisar em que medida a concepção de justiça de John Rawls comporta a defesa da propriedade privada individual. Para alcançar tal objetivo, será necessário começar indicando os contornos do conceito de propriedade que se pretende discutir.

A propriedade talvez seja o instituto de maior influência no ordenamento jurídico da sociedade contemporânea. No contexto do direito brasileiro, em especial, a propriedade adquire ainda maior relevância, quando consideradas as grandes disparidades decorrentes da desigualdade de renda e riqueza existentes em nossa sociedade.

O conceito de propriedade pode se referir a diversos conteúdos ou a uma multiplicidade de estatutos que influem na relação entre os diferentes objetos e sujeitos sobre os quais pode recair o domínio ${ }^{1}$ e a titularidade dos direitos, tais como a propriedade material, que abrange e a propriedade dos bens móveis e a propriedade dos bens imóveis, e a propriedade imaterial, que compreende a propriedade literária e artística, a propriedade industrial, entre outros.

Na concepção capitalista, a propriedade pode representar um bem ou meio de produção, como é o caso da propriedade sobre a terra, quando responsável pela geração de alimentos e matéria-prima para a indústria. Sob essa perspectiva, a propriedade, aliada à força de trabalho, constitui uma das bases materiais que assegura a sobrevivência do homem do campo ${ }^{2}$.

No aspecto filosófico, além da propriedade material, deve-se ressaltar que, durante os séculos XVII e XVIII, a propriedade adquiriu significado mais abrangente, passando a incluir "tudo que alguém reivindica como sendo seu, começando pela vida e pela liberdade", e que é essa concepção moderna de propriedade que dá origem aos direitos humanos (PIPES, 2001, p. 14).

\footnotetext{
${ }^{1} \mathrm{O}$ domínio, nesse sentido, representa o direito de propriedade sobre as coisas corpóreas. ${ }^{2} \mathrm{Na}$ definição de Piketty (2014, p. 51), esse tipo de propriedade constitui uma forma de capital, pois representa o "“....] conjunto de ativos não humanos que podem ser adquiridos, vendidos e comprados em algum mercado".
} 
Essa pluralidade de estatutos relativa ao direito de propriedade e aos seus diferentes conteúdos históricos e normativos demanda que a propriedade seja estudada separadamente, de acordo com os elementos históricos e materiais ${ }^{3}$ que a distinguem:

Em cada período histórico, a propriedade manifesta-se por meio da apropriação de bens e das relações jurídicas estabelecidas com eles. Daí se poder falar em uma descontinuidade conceitual: a concepção de propriedade é temporalmente determinada e condicionada por fatores sociais, econômicos e ambientais. (BENATTI, 2003, p. 25)

O tema da propriedade também está relacionado com a liberdade ${ }^{4}$. O termo liberdade possui significados diversos, podendo expressar a liberdade civil e política, a liberdade econômica, a liberdade individual, a liberdade de expressão e reunião, e a liberdade de consciência e de pensamento.

No domínio econômico constata-se a proteção do direito de propriedade a partir da liberdade de iniciativa. Sobre o papel do Estado, em alguns aspectos, tem-se a noção de liberdade negativa, caracterizada pela não interferência nos domínios da propriedade. Em Rawls (2008), encontra-se uma noção de liberdade das pessoas que não pode ser violada nem por leis ou instituições injustas, mesmo que visem o bem-estar da coletividade. Essa noção vincula o papel da justiça à preservação da liberdade do indivíduo em relação à vontade da maioria ${ }^{5}$.

\footnotetext{
${ }^{3}$ Podemos tomar como exemplo a categoria específica da propriedade sobre os bens imóveis. Nessa categoria, entretanto, existe outra peculiaridade que toca esse tipo de propriedade, que diz respeito à propriedade sobre bens de produção, como ocorre no caso da propriedade rural.

${ }^{4}$ Em Propriedade e Liberdade, Pipes (2001, p. 15) tenta demonstrar essa interligação entre os conceitos com base em evidências históricas: “[...] minha hipótese inicial dizia que há uma interligação íntima entre garantias públicas de propriedade e liberdade individual: que enquanto a propriedade de certa forma existe sem liberdade, o contrário é inconcebível".

5 Neste artigo, o termo liberdade será utilizado em suas diferentes acepções, mas na maioria das vezes procurando vincular a liberdade em seus aspectos mais básicos (liberdades fundamentais inerentes à dignidade da pessoa humana), que dizem respeito à liberdade de escolha das pessoas (liberdade para agir).
} 
O mesmo vale para a igualdade, cujo termo também pode ser relacionado com a justiça. Em Aristóteles (1999), a igualdade tem relação com a isonomia: tratar os iguais de modo igual e os diferentes na medida de suas desigualdades.

O termo também guarda relação com a igualdade formal, que expressa a igualdade de todos perante a lei. Essa igualdade também pode representar igualdade na aplicação da lei. Como reivindicação de natureza moral, pode-se invocar uma igualdade de oportunidades, de tratamento, de respeito e de consideração entre os indivíduos, que, de certo modo, diz respeito aos direitos e vantagens e aos deveres e encargos.

Embora possa haver certa discordância, pode-se afirmar que o pressuposto da igualdade material, em grande medida, está relacionado a uma espécie de igualdade social ou de fato, ao dever de compensação das desigualdades sociais, econômicas e culturais ${ }^{6}$ (SARLET et al., 2014, p. 543).

No debate sobre o direito de propriedade nunca houve um consenso. Mas reivindicações em torno desse direito não estão apenas vinculadas a questões abstratas de cunho moral, pois demandam análises que devem ser sensíveis à realidade.

Pipes (2001, p. 24) sintetiza da seguinte forma as divergências teóricas decorrentes das relações que a propriedade apresenta com a política, a ética, a economia e a psicologia no contexto distributivo:

a) No aspecto político, sustenta-se que a distribuição da propriedade desempenha um papel de estabilidade e limitação do poder do governo. Em sentido contrário, a desigualdade nessa distribuição geraria instabilidade social.

b) No aspecto ético (moral), a distribuição da propriedade seria legítima à medida que se garante a propriedade dos frutos do próprio trabalho. Em sentido contrário, argumenta-se que essa lógica requer que todos tenham as mesmas oportunidades para adquirir propriedade.

\footnotetext{
${ }^{6}$ No aspecto deste trabalho, parte-se da noção de Sen (2008), segundo a qual, a igualdade sempre é levada em consideração quando se discute a ideia de justiça, de forma que a igualdade específica de tratamento será direcionada ao enfoque das capacidades humanas.
} 
c) No aspecto econômico, sustenta-se que a propriedade é o meio mais eficiente de produção de riqueza. Em sentido contrário, argumenta-se que a busca do ganho pessoal decorrente das atividades econômicas leva a uma competição destrutiva.

d) No aspecto psicológico, a propriedade estimularia a consciência de identidade e a autoestima. Em sentido contrário, argumenta-se que a noção de propriedade corrompe a personalidade e promove a cobiça.

Esses aspectos serão tratados procurando relacionar o papel que a propriedade desempenha no contexto do desenvolvimento humano. Para realizar esse exercício, será necessário entender como a propriedade pode ser compreendida no contexto da justiça distributiva.

\section{A Compreensão da Propriedade no Contexto da Justiça Distributiva}

Pode-se afirmar, com base em Fleischacker (2006), que o sentido antigo de justiça distributiva não reconhece que a estrutura básica ${ }^{7}$ de distribuição de recursos na sociedade é uma questão de justiça.

No sentido antigo, a justiça distributiva é virtude privada e não tarefa para o Estado. O sentido moderno invoca o Estado para garantir que alguns bens sejam distribuídos por toda a sociedade de modo que todas as pessoas possam suprir-se com certo nível de recursos materiais.

Com esse pensamento, os governos europeus, até o final do século XVIII, quando invocados, atuavam de forma assistencialista, justificando suas políticas com base na virtude da caridade e não por ser questão de justiça ${ }^{8}$.

\footnotetext{
${ }^{7}$ Será retomada adiante a explicação do que representa essa estrutura básica e qual a relação disso com as normas que regulam a propriedade.

${ }^{8}$ É possível ver, nesse sentido, os comentários de Fleischacker (2006, p. 72 e ss.) sobre as Poor Laws (Leis de Assistência aos Pobres) inglesas.
} 
Por volta do final do século [XVIII], começamos a ver claramente uma crença segundo a qual o Estado pode, e deve, tirar as pessoas da pobreza, e que ninguém merece, e nem precisa, ser pobre, e que, em vista disso, é tarefa do Estado, pelo menos em parte, distribuir ou redistribuir bens. No entanto, essa crença não era tão difundida, e só veio a ocupar o centro do palco na revolta mal sucedida liderada por "Graco" Babeuf" no final da Revolução Francesa. (FLEISCHACKER, 2006, p. 80)

O recorte histórico é importante porque marca uma mudança de enfoque. No século XVIII, a noção de justiça distributiva como hoje a conhecemos, ainda não existia, e filósofos da monta de David Hume, Rousseau ${ }^{10}$, Adam Smith e Kant, contribuíram para estabelecer as bases que possibilitariam analisar, como atualmente se discute, qual é o papel do Estado na ajuda aos pobres (FLEISCHACKER, 2006).

Ainda que desvinculada dessa noção mais atual de justiça distributiva, a propriedade, contextualizada devidamente nesse período histórico, foi concebida como elemento diretamente ligado à existência humana. Segundo Silva (2008, p. 240), é nessa configuração que a propriedade liberal será defendida por pensadores como Locke, Hobbes e Benjamin Constant, sendo a propriedade vista como o meio de que necessita o homem para sua subsistência e ociosidade.

Segundo Pipes (2001, p. 48),

[...] no curso do século XVII, tornou-se amplamente aceita na Europa Ocidental, a idéia de que existe uma Lei da Natureza que é racional, que não muda e é imutável, e transcende as leis humanas (positivas); que um aspecto da Lei da Natureza é a inviolabilidade

\footnotetext{
${ }^{9}$ Babeuf foi líder de uma tentativa de golpe em 1796.

${ }^{10}$ Sobre Rousseau, é interessante notar que, conforme observa Brito Filho (2014, p. 27), embora reconheça o direito de propriedade, não defende uma propriedade desmedida, em detrimento do conjunto da sociedade, já que, quando trata das "[...] condições para autorizar o direito do primeiro ocupante, [...] lista, como segunda e terceira condições, 'que só se ocupe a quantidade que se necessita para sobreviver', e que se tome posse 'pelo trabalho e pela cultura da terra, único sinal de propriedade que, na falta dos títulos jurídicos, deve ser respeitado por alguém"”.
} 
da propriedade privada; e que os soberanos têm a obrigação de respeitar os pertences de seus súditos, mesmo quando negam a eles o direito de participar dos negócios do Estado.

Entretanto, como afirma Fleischacker (2006, p. 42), “[...] nem um único pensador jurisprudencial antes de Smith colocou a justificação de direitos de propriedade sob o título de justiça distributiva [...]", sendo que “[...] reivindicações de propriedade, assim como violações de propriedade, eram questões para a justiça comutativa ${ }^{11}$ ".

As reflexões de Hugo Grócio deram origem ao conceito de direitos inalienáveis, conceito que integra a base da concepção moderna de direitos humanos quando ele escreveu entre 1618-1621, enquanto esteve preso por dissidência política, sobre a diferença entre as coisas alienáveis e inalienáveis pertencentes aos indivíduos.

As primeiras aplicavam-se a "coisas que por sua natureza podem pertencer a uma pessoa assim como a outra". Já as coisas inalienáveis seriam as que "pertencem tão essencialmente a um homem que não poderiam pertencer a outro, tais como a vida, o corpo, a liberdade e a honra". Essa distinção permitiu a Grócio negar às pessoas o direito de abrir mão de sua liberdade, colocando-se em regime de servidão (PIPES, 2001, p. 52).

Foram David Hume e Adam Smith que primeiro apresentaram o sistema da propriedade privada como problema central na questão dos pobres, quando defenderam que a concentração da propriedade se torna imoral numa sociedade em que os pobres devam sofrer enquanto os abastados têm seus direitos protegidos. Assim, são referidos autores os primeiros a fazer do sofrimento dos pobres um problema para a justificação da propriedade.

\footnotetext{
${ }^{11}$ Justiça comutativa, antes vista como justiça corretiva, numa tradição histórica significa proteção contra injúrias, ou seja, a responsabilização por danos causados às vítimas de acordo com a extensão desses danos. Partindo de Tomás de Aquino, Fleischacker (2006, p. 43) demonstra que até o direito de necessidade é visto sob a justiça comutativa, à medida que Aquino defendeu que se apropriar do que se necessita em situação de desespero (fome) não constituiria violação de propriedade, nem mesmo furto justificado.
} 
Somente quando entendemos que um sistema de direitos estritos de propriedade no seu todo protege a liberdade de cada um na sociedade, e que a longo prazo esse sistema leva cada um a uma situação melhor do que estaria sob uma distribuição igualitária de bens, devemos aceitar tais direitos como justificados. (FLEISCHACKER, 2006, p. 59)

Na concepção capitalista, a propriedade, por ser recurso privado ${ }^{12}$, produz exclusão. Por isso, é importante que a mesma seja discutida no aspecto da justiça distributiva ${ }^{13}$.

Sem dúvida, no sistema jurídico brasileiro, a gradativa constitucionalização do direito privado, com o reconhecimento da possibilidade de intervenção estatal em aspectos que antes estavam relegados à esfera das relações privadas, incluindo a garantia da propriedade, atinge seu ápice com a Constituição de 1988.

É ainda necessário destacar que a concepção de justiça social materializada no texto constitucional, no sentido aristotélico-tomista original, diz respeito ao dever de cada indivíduo para com a comunidade, tomada no conjunto de seus membros, mas não o contrário, ou seja, o que é devido pela comunidade a cada um de seus membros.

$\mathrm{Na}$ tradição antiga, esse segundo aspecto - o que é devido pela comunidade a cada um de seus membros? - é tratado pela justiça distributiva. E, a partir de Rawls (2008), com a primeira edição de Uma Teoria da Justiça, em 1971, o conceito de justiça distributiva é redefinido, quando este autor desvincula referido conceito da noção de mérito e incorpora exigências de imparcialidade para inverter a lógica e estabelecer que a concepção de bem não pode sobrepor-se à concepção do que é justo, conforme será visto.

\footnotetext{
${ }^{12}$ Essa limitação diz respeito à privatização do bem, ou seja, pelo direito de propriedade restringe-se individualmente o uso do recurso, impedindo-se o livre acesso.

${ }^{13}$ Do mesmo modo, a justiça social, objetivo constitucional contemporâneo que orienta a ordem econômica, não pode ser entendida fora da discussão sobre qual deve ser o papel do Estado no domínio econômico frente à liberdade de iniciativa.
} 


\section{A Defesa da Propriedade a partir da Visão de Rawls}

A teoria de Rawls (2008) é denominada justiça como equidade, e segundo a redefinição proposta, a justiça tem de ser vista com relação às exigências de imparcialidade, ou seja, deve levar em conta os interesses e as preocupações de todos, evitando que sejamos influenciados por nossos próprios interesses, prioridades pessoais ou preconceitos (SEN, 2011, p. 84).

Para Rawls (2008, p. 4), a justiça é a virtude primeira das instituições sociais, sendo que a liberdade das pessoas não pode ser violada por leis e instituições injustas, mesmo que visem o bem-estar da coletividade. Desse modo, o papel da justiça seria a preservação da liberdade do indivíduo em relação à vontade da maioria.

Como decorrência da individualidade humana, a justiça só deveria se ocupar da distribuição de bens primários sociais, que são os bens necessários à busca de praticamente qualquer fim ${ }^{14}$, em vez de se ocupar da questão sobre o que constitui o bem humano supremo (FLEISCHACKER, 2006, p. 161).

Um regime democrático deve aceitar a enorme diversidade de valores culturais e formas pelas quais as pessoas compreendem o mundo. E uma concepção de justiça condizente com o pluralismo deve ser imparcial em relação às diversas visões compreensivas acerca do que constitui uma vida digna (RAWLS, 2008). Segundo Brito Filho (2014, p. 35), Rawls inverte a lógica Aristotélica, para mostrar que a concepção de bem, ainda que seja fruto da comunidade, não pode sobrepor-se à concepção do que é justo.

Conforme observa Vita (2008, p. 20), na apresentação da edição brasileira de Uma teoria da justiça, de Rawls (2008), uma sociedade democrática (que é a expressão de uma sociedade justa) “[...] é aquela cujas

\footnotetext{
${ }^{14}$ Os bens primários sociais seriam os direitos, liberdades, oportunidades, renda, riqueza além do autorrespeito: “[...] são bens sociais tendo em vista sua conexão com a estrutura básica; as liberdades e as oportunidades são definidas pelas normas das principais instituições, e a distribuição de renda e de riqueza é regida por elas.” (RAWLS, 2008, p. 76 e 110).
} 
instituições sociais, econômicas e políticas tratam seus membros como pessoas moralmente iguais".

Para Citadino (2004, p. 99), Rawls parte do pressuposto de que há uma ideia intuitiva implícita na cultura democrática que descreve a sociedade como um sistema equitativo de cooperação social entre pessoas livres e iguais, que têm a capacidade de ter uma concepção de bem e um senso de justiça.

É possível perceber, tendo em vista esse sistema de cooperação concebido por Rawls, que ele adota como pressuposto de sua teoria uma noção de igualdade humana fundamental. Isso significa que a liberdade e igualdade de todos, individualmente concebida, constituem as propriedades morais básicas assentes na capacidade que cada cidadão possui para definir a sua concepção de bem e para ter um sentido de justiça (ROSAS, 2011, p. 22).

Para Rawls (2008, p. 8), a estrutura básica da sociedade é o objeto da justiça, pois é aqui que é definido o modo como as principais instituições sociais distribuem os direitos e os deveres fundamentais e a divisão de vantagens provenientes da cooperação social.

Como esclarece Vita (2008, p. 30, grifo nosso), a estrutura básica da sociedade

[...] abrange as normas de distribuição de direitos legais, as normas que determinam as formas de acesso às posições de poder e autoridade, as normas e instituições, incluindo o sistema educacional, que determinam o acesso a profissões e a posições ocupacionais; e o complexo de instituições, incluindo-se aí as normas que regulam a propriedade, o direito de herança e o sistema tributário e de transferências, que determinam a distribuição de renda e da riqueza na sociedade.

Assim, as instituições sociais representam o conjunto de normas públicas que define cargos e posições, direitos e deveres, poderes e imunidades (RAWLS, 2008, p. 66). Correspondem à Constituição, às principais leis e arranjos no domínio da propriedade, da fiscalidade, ou ainda outros 
aspectos que Rawls não costuma explicitar em pormenor, como o conjunto das instituições que asseguram os direitos na cobertura dos riscos sociais, na educação, na saúde etc. (ROSAS, 2011, p. 25).

O objetivo da justiça, que é diferente do seu objeto, consiste na definição dos princípios que, aplicados à estrutura básica, fazem com que a sociedade seja bem ordenada (ROSAS, 2011, p. 25). Ou seja, “[...] o conceito de justiça é definido, então, pelo papel de seus princípios na atribuição de direitos e deveres e na definição da divisão apropriada das vantagens sociais" (RAWLS, 2008, p. 12).

Brito Filho (2014, p. 36) explica que Rawls trabalha num ambiente limitado ${ }^{15}$, que considera ser ideal para sua teoria, e pressupõe uma sociedade bem ordenada, ou seja, aquela que é regulada de forma efetiva por uma concepção pública de justiça, e é moldada para promover o bem de seus membros ${ }^{16}$.

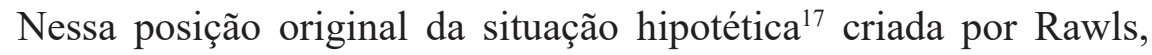
as partes estão cobertas pelo véu da ignorância, o que significa que elas não sabem como as várias alternativas irão afetar sua situação pessoal, de modo que os princípios serão adotados de forma imparcial. Com essa formulação, pretende demonstrar como as partes chegariam a um consenso sobre os princípios de justiça que seriam escolhidos.

Por isso, presume-se que as partes desconhecem seu lugar na sociedade, sua classe ou seu status social, sua própria sorte na distribuição dos dotes e das capacidades naturais, inteligência ou força, nem mesmo sua

15 "Pode-se dizer que o que Rawls faz é criar um ambiente imaginário hipotético, e que serve de base para que ele indique quais, em sua visão, são os princípios que ele imagina adequados para reger as principais instituições sociais e que revelam a escolha de dois grandes ideais políticos: a liberdade e a igualdade.” (BRITO FILHO, 2014, p. 39).

${ }^{16}$ Sobre o conceito de sociedade bem-ordenada em Rawls (2008), veja-se o $§ 69$ do capítulo VIII, p. 560 e ss.: “[...] é uma sociedade na qual todos aceitam e sabem que os outros aceitam os mesmos princípios de justiça, e as instituições sociais básicas atendem e se sabem que atendem a esses princípios".

${ }^{17}$ Segundo Rawls (2008, p. 146), a posição original “[...] é uma situação na qual as partes são igualmente representadas como pessoas morais, e o resultado não é condicionado por contingências arbitrárias nem pelo equilíbrio relativo das forças sociais". 
própria concepção do bem ou as particularidades de seu projeto racional de vida (RAWLS, 2008, p. 166).

Essa ausência de informações garante que as partes não sejam influenciadas por seus próprios interesses, prioridades pessoais e preconceitos, de forma a escolherem os princípios visando o benefício próprio.

Além disso, Rawls (2008, p. 173) pressupõe que as pessoas são seres racionais e desinteressados ${ }^{18}$, que embora não tenham informações suficientes a respeito de seus objetivos, possuem conhecimento suficiente para hierarquizar alternativas, de forma a proteger suas liberdades, e ampliar suas oportunidades e os meios de promoverem seus objetivos, quaisquer que sejam.

Sustenta que os princípios de justiça escolhidos em um acordo inicial demandariam igualdade na atribuição dos direitos e dos deveres fundamentais, e a aceitação de que as desigualdades sociais e econômicas só serão justas se resultarem em vantagens recompensadoras para todos, em especial para os membros menos favorecidos da sociedade.

A primeira formulação dos princípios é apresentada da seguinte forma:

Primeiro: cada pessoa deve ter um direito igual ao sistema mais extenso de iguais liberdades fundamentais que seja compatível com um sistema similar de liberdades para as outras pessoas. Segundo: as desigualdades sociais e econômicas devem estar dispostas de tal modo que tanto (a) se possa razoavelmente esperar que se estabeleçam em benefício de todos como (b) estejam vinculadas a cargos e posições acessíveis a todos. (RAWLS, 2008, p. 73)

Já a formulação definitiva dos princípios, é acrescida de duas regras de prioridade:

${ }^{18}$ Quanto ao desinteresse, o autor explica: “[...] as pessoas que se encontram na posição original tentam reconhecer princípios que promovam seu sistema de objetivos da melhor forma possível. Para isso, tentam garantir para si mesmas o mais alto índice de bens primários sociais, já que isso lhes possibilita promover sua concepção do bem da maneira mais eficaz, seja qual for essa concepção. As partes não procuram conceder benefícios nem impor prejuízos umas às outras; não têm motivações de afeto, nem de rancor. Nem tentam levar vantagens umas sobre as outras" (RAWLS, 2008, p. 175). 
Primeiro princípio

Cada pessoa deve ter um direito igual ao mais abrangente sistema total de liberdades básicas iguais que seja compatível com um sistema similar de liberdades para todos.

Segundo princípio

As desigualdades sociais e econômicas devem ser dispostas de modo a que tanto:

(a) se estabeleçam para o máximo benefício possível dos menos favorecidos que seja compatível com as restrições do princípio de poupança justa, como

(b) estejam vinculadas a cargos e posições abertos a todos em condições de igualdade eqüitativa de oportunidades.

Primeira regra de prioridade (a prioridade da liberdade)

Os princípios da justiça devem ser dispostos em ordem lexical e, portanto, só se podem restringir as liberdades básicas em nome da própria liberdade. Existem dois casos:

(a) uma liberdade menos extensa deve fortalecer o sistema total de liberdades partilhado por todos;

(b) uma liberdade desigual deve ser aceitável para aqueles que têm menor liberdade.

Segunda regra de prioridade (a prioridade da justiça sobre a eficiência e o bem-estar)

O segundo princípio de justiça precede lexicalmente o princípio de eficiência e o princípio da maximização da soma de vantagens; e a igualdade eqüitativa de oportunidades precede o princípio de diferença. Há dois casos:

(a) a desigualdade de oportunidades deve aumentar as oportunidades daqueles que têm menos oportunidades;

(b) uma taxa elevada de poupança deve, pesando-se tudo, mitigar o ônus daqueles que carregam esse fardo. (RAWLS, 2008, p. 376)

Esses princípios de justiça se aplicam à estrutura básica da sociedade, e se a estrutura básica estiver definida de acordo com eles, então a sociedade será justa, sejam quais forem os resultados obtidos por cada um dos seus membros (ROSAS, 2011, p. 25). 
Rawls começa pelas liberdades fundamentais, pois distingue os aspectos que as definem e as garantem dos aspectos que estabelecem e especificam as desigualdades sociais e econômicas.

As liberdades fundamentais, de acordo com o primeiro princípio, devem ser iguais, e correspondem à liberdade política, à liberdade de expressão e reunião, à liberdade de consciência e de pensamento, à liberdade individual (integridade da pessoa), "[...] além do direito à propriedade pessoal e a proteção contra prisão e detenção arbitrárias, segundo o conceito de Estado de Direito.” (RAWLS, 2008, p. 74).

Rawls (2008, p. 75) exclui expressamente dessa lista de liberdades o direito a certos tipos de propriedade ${ }^{19}$ (por exemplo, a propriedade dos meios de produção ${ }^{20}$ ), por entender que não são fundamentais e, portanto, não estão protegidos pela prioridade do primeiro princípio ${ }^{21}$.

Esse direito de propriedade, que Rawls (2003, p. 161, nota 36) define genericamente como um direito à propriedade pessoal, não é esmiuçado em suas obras, mas inclui, pelo menos certas formas de propriedade material, como a habitação.

${ }^{19}$ Em justiça como equidade, Rawls (2003, p. 161) retoma esse raciocínio e também exclui dessa lista de liberdades o direito de propriedade privada de recursos naturais e a propriedade decorrente de transmissão por herança. Em verdade, Rawls não nega a proteção desses tipos de propriedade. Mas entende que essa regulação deve ser feita num estágio posterior, e desde que os direitos e liberdades básicos se mantenham.

${ }^{20}$ Rawls não analisa se a aplicação do segundo princípio pode justificar a limitação do direito a propriedade dos meios de produção quando isso implicar a redução das desigualdades sociais e econômicas e no aumento da igualdade de oportunidade.

${ }^{21} \mathrm{O}$ entendimento de Rawls quanto à importância do direito a propriedade dos meios de produção em sua teoria de justiça é fundamental para estabelecer as bases do presente trabalho como será analisado mais adiante. Para evitar um possível erro de tradução, recorreu-se à $1^{\mathrm{a}}$ edição de sua obra em português, cuja transcrição é a seguinte (RAWLS, 1997, p. 66): "Sem dúvida, liberdades que não constam nessa lista, por exemplo, o direito a certos tipos de propriedade (digamos, os meios de produção) [...], não são básicas [ou fundamentais, como o termo é traduzido na $3^{a}$ edição]; portanto, não estão protegidas pela prioridade do primeiro princípio". Na versão original, o texto segue da seguinte forma (RAWLS, 1999, p. 54): "Of course, liberties not on the list, for example, the right to own certain kinds of property (e.g., means of production) $[\ldots]$ are not basic; and so they are not protected by the priority of the first principle". 
O segundo princípio se aplica à distribuição de renda e riqueza e à estruturação dos cargos de autoridade e responsabilidade das organizações. Rawls aceita que a distribuição de renda e riqueza sejam desiguais, desde que "[...] tragam o maior benefício possível para os menos favorecidos e desde que se tenha igualdade de oportunidades" (BRITO FILHO, 2014, p. 44).

Assim, o segundo princípio de justiça combina o princípio da igualdade equitativa de oportunidades com o princípio de diferença.

A igualdade equitativa de oportunidades significa dizer que aqueles que têm capacidades e habilidades similares devem ter oportunidades similares de vida, ou seja, que as posições das carreiras abertas aos talen$\operatorname{tos}^{22}$ não estejam acessíveis apenas no sentido formal, mas que todos tenham oportunidades reais de alcançá-las. É o recurso que Rawls (2008, p. 88) utiliza para tentar corrigir injustiças decorrentes de fatores arbitrários, como a classe social (circunstâncias sociais) ou os dotes naturais.

Já o princípio de diferença ${ }^{23}$ representa espécie de desigualdade controlada, e indica a posição específica a partir da qual as desigualdades sociais e econômicas da estrutura básica devem ser julgadas segundo um critério de justiça. Para Rawls (2008, p. 100), as desigualdades sociais e econômicas só são moralmente aceitáveis se propiciarem o máximo benefício esperado para os membros menos favorecidos da sociedade ${ }^{24}$.

\footnotetext{
${ }^{22}$ Rawls (2008, p. 80) explica: “[...] um sistema social aberto, [...] no qual as carreiras estão abertas aos talentos, [...] afirma, então, que a estrutura básica que satisfaça ao princípio da eficiência e na qual os cargos estejam abertos aos que estão capacitados e dispostos a lutar por eles levará à distribuição justa".

${ }^{23} \mathrm{O}$ princípio de diferença também representa um acordo para considerar a distribuição dos talentos naturais em certos aspectos um bem comum, de modo que aqueles que tenham sido favorecidos pela loteria natural só possam beneficiar-se de sua boa sorte em condições que melhorem a situação dos menos afortunados (RAWLS, 2008, p. 121). ${ }^{24}$ Uma interpretação do princípio de diferença a partir da noção de direitos humanos pode ser feita da seguinte forma: nenhum indivíduo pode ter menos do que o mínimo necessário para sua sobrevivência, o que se expressa pelo conjunto mínimo de direitos necessários à preservação da dignidade da pessoa humana. Essa noção remete à concepção kantiana de dignidade (RAWLS, 2008, p. 221).
} 
Entretanto, fica claro que o aumento da igualdade não pode implicar a diminuição da liberdade, pois todos têm direito a ter os mesmos direitos e liberdades, e nenhuma medida que aumente o bem-estar das pessoas é admissível se isso implicar violação das liberdades.

A prioridade da liberdade significa que, sempre que as liberdades fundamentais podem ser de fato instituídas, não é permitido trocar uma liberdade menor ou desigual por uma melhoria do bem-estar econômico. É só quando as circunstâncias sociais não permitem a instituição desses direitos fundamentais que se pode consentir em sua limitação; e mesmo assim, essas restrições só podem ser admitidas na medida em que forem necessárias para preparar o caminho para o momento em que não mais se justifiquem. (RAWLS, 2008, p. 185)

Por isso, os princípios estão dispostos em ordem lexical, ou seja, em ordem de prioridade. Na concepção de Rawls (2008, p. 302), maiores vantagens sociais e econômicas não justificam nem a violação nem a limitação das liberdades fundamentais (que devem ser iguais para todos). "A primazia da liberdade significa que a liberdade só pode ser limitada em nome da própria liberdade".

Rawls, desse modo, pode ser definido como um liberal-igualitário. O liberalismo defendido por Rawls e os autores que seguem seu pensamento, mais se assemelha aquilo que os autores latino-americanos e europeus definem como social-democracia ${ }^{25}$, não se confundindo, portanto, com o liberalismo libertário do Estado mínimo.

Conforme explica Carlos Henrique Cardim, na apresentação para a edição brasileira do livro O Liberalismo Político (RAWLS, 2000, p. 5), o compromisso dos sociais-democratas é com a igualdade de resultados, enquanto o compromisso dos liberais americanos é com a igualdade de oportunidades:

${ }^{25}$ Veja-se, nesse sentido, artigo de Calazans, Disponível em: http://www.conjur.com. br/2013-fev-19/paulo-calazans-dworkin-deixa-inestimavel-legado-teoria-direito. Acesso em: 30 dez. 2014. 
O termo liberal não tem nos Estados Unidos a mesma acepção que lhe é atribuída entre nós e na Europa. Os conservadores norte-americanos entendem-no como sinônimo de socialista, o que tampouco faz sentido no Brasil [...]. A corrente forte (liberal, em grande medida identificada com o Partido Democrata) caracteriza-se pela adoção de mecanismos oficiais destinados a promover a elevação dos padrões de renda da minoria que não consegue fazê-lo através do mercado (New Deal de Roosevelt; Big Society de Lyndon Johnson etc.). Assim sendo, ela mais se assemelha à social-democracia européia, ainda que esta só se tenha oficializado no Congresso de Godsberg (novembro de 1959), do Partido Social-Democrata Alemão, que rompe com o marxismo e renuncia à sociedade sem classes, se bem que sem abdicar de uma certa igualdade de resultados (o compromisso dos liberais é com a igualdade de oportunidades). O liberal americano pode, pois, ser qualificado de social-democrata.

Segundo Rawls (2008, p. 127), a interpretação democrática dos dois princípios está baseada nas ideias de liberdade, igualdade e fraternidade: "[...] a liberdade corresponde ao primeiro princípio; a igualdade, à ideia de igualdade contida no primeiro princípio juntamente com a igualdade equitativa de oportunidades; e a fraternidade, ao princípio de diferença".

Essa leitura possibilita caracterizar os bens primários sociais como sendo equivalentes aos direitos fundamentais ${ }^{26}$. Esses direitos fundamentais gozam de essencialidade e substancialidade, o que permite caracterizá-los como um “[...] conjunto mínimo de direitos necessário para assegurar uma vida do ser humano baseada na liberdade, igualdade e na dignidade" (RAMOS, 2005, p. 19).

Para Brito Filho (2014, p. 45), o marco da contribuição de Rawls está na defesa vigorosa da igualdade como ideal político, rompendo com

\footnotetext{
${ }^{26}$ No mesmo sentido, Brito Filho (2014, p. 245) demonstra que, usando a terminologia consagrada no Direito, os bens valiosos tratados pela filosofia política, são os bens fundamentais, e que cabe ao Estado a transferência do mínimo, nesse caso, os direitos fundamentais. Os bens primários são "[...] todos os fundamentais, indicados a partir do artigo $5^{\circ}$, Constitucional, em conjunto que inclui os direitos e garantias individuais e coletivos, os direitos sociais, os direitos de nacionalidade e os direitos políticos".
} 
a visão liberal clássica, que até aquele momento estava centrada na dicotomia da liberdade-propriedade privada.

Ocorre que, embora faça uma defesa vigorosa da propriedade privada, o fato de Rawls não considerar o direito a propriedade dos meios de produção uma questão básica que mereça ser protegida pelo primeiro princípio, em nossa impressão, configura um claro problema.

A evolução do capitalismo até sua fase atual está intimamente ligada ao desenvolvimento da economia agrária. Bobbio et al. (2007, p. 1041) apontam que essa fase ${ }^{27}$ teve início a partir da teoria da renda da terra, de David Ricardo, em 1817, naquilo que se convencionou chamar de questão agrária: um conjunto de problemas sociais e econômicos ligados ao setor primário da economia, incluindo também aqueles relacionados com os trabalhadores da terra.

A influência teórica de Ricardo (1722-1823) contribuiu para a afirmação do liberalismo clássico, pois referido autor estabeleceu as necessárias conexões com alguns conceitos básicos, como a taxa de lucro, a acumulação de capital e o consequente antagonismo que se formou entre duas categorias: os proprietários de terra e os capitalistas ${ }^{28}$.

É recorrente na literatura a análise de que a miséria e a exclusão social produzidas no sistema capitalista também estão relacionadas e de-

${ }^{27}$ Segundo Lenz (1993), o estudo da importância da terra na composição dos fluxos monetários, sua relação com a acumulação de capital, com o lucro e com a formação da renda dos agricultores, na verdade, tem sua origem no capitalismo mercantil dos séculos XV a XVII. Esse movimento de transição se inicia já na idade média, quando se verifica uma pequena e gradativa mudança na configuração das propriedades feudais, em que algumas terras passam a ser arrendadas e a mão de obra começa a ser esporadicamente remunerada com salários.

${ }^{28}$ Segundo Ricardo (1979, p. 255), a renda representa o pagamento feito pelo produtor (capitalista-arrendatário) ao dono da terra (proprietário rural). O proprietário, nessa perspectiva, não é aquele que trabalha a terra, é apenas quem usufrui a renda em decorrência de sua condição de dono do bem. Para Ricardo, a renda se distribuía da seguinte forma: o proprietário da terra é aquele que usufrui a renda. $\mathrm{O}$ fazendeiro-arrendatário é aquele que usufrui o lucro e juros do capital (é o capitalista). E o trabalhador é aquele que recebe salário pela sua mão de obra. Faz a defesa fazendeiro-arrendatário e condena o proprietário da terra 
correm em grande medida do alto grau de desigualdade na distribuição da terra, em especial quando se considera que boa parte da população mundial ainda reside no campo ${ }^{29}$.

Ainda que seja uma teoria de base ideal, esses pontos deveriam ser levados em consideração, pois todas as sociedades humanas têm sua fundação baseada na atividade agrária, ainda que consideremos as economias de subsistência de alguns povos tradicionais, pois é a partir da revolução agrícola, segundo indicam os historiadores, que os seres humanos começam a acumular propriedade privada ${ }^{30}$.

Em alguns países, a exemplo do Brasil, a principal fonte de formação e apropriação de riqueza no campo é a terra. Piketty (2014, p. 46) destaca que a tensão entre proprietário e camponês, entre aquele que possui a terra e aquele que a cultiva, entre o que recebe os lucros e o que os possibilita, está no cerne da desigualdade social e de todas as revoltas e rebeliões das sociedades tradicionais.

Por esses motivos, considera-se que o primeiro princípio de Rawls deveria abarcar a liberdade fundamental de que os indivíduos possam acumular propriedade privada sobre a terra, de modo que a aplicação do segundo princípio pode e deve justificar a limitação desse direito quando isso implicar na redução das desigualdades sociais e econômicas e no aumento da igualdade de oportunidades.

Esse argumento, inclusive, justifica positivamente o fato do sistema jurídico brasileiro ter conferido uma proteção constitucional especial para a propriedade rural, especialmente quando condiciona o exercício desse direito ao cumprimento de uma função social.

\footnotetext{
${ }^{29}$ Pelas teorias econômicas de influência marxista, já que quem não detém o capital (no caso das economias rurais, as terras), tem como única alternativa vender sua força de trabalho (mais-valia). Logo, a concentração do capital (terra) produz exclusão social.

${ }^{30}$ Veja-se Harari (2015), por todos.
} 


\section{Conclusão}

Pode-se afirmar que, na concepção de Rawls, a propriedade privada individual (à exceção da propriedade dos meios de produção, da propriedade sobre os recursos naturais e da propriedade decorrente de transmissão por herança) é um bem primário, pois as instituições sociais que a regulam (à exemplo da Constituição e do Código Civil) estão abrangidas na estrutura básica da sociedade.

O direito de propriedade é considerado por Rawls uma liberdade fundamental e está protegido pelos princípios de justiça, em especial o primeiro. Isso justifica, do ponto de vista teórico, que o direito de propriedade merece ser protegido enquanto direito fundamental, pelo simples fato de ser algo inerente à liberdade de escolha dos indivíduos.

Embora faça uma defesa vigorosa da propriedade privada, Rawls não considera o direito à propriedade da terra uma questão básica que mereça ser protegida pelo primeiro princípio, configurando um claro problema na aplicação da teoria de justiça rawlsiana, já que todas as sociedades humanas têm suas estruturas fundantes baseadas na atividade agrária.

Um dos objetivos do presente ensaio, além de analisar a teoria de Rawls, foi defender que o primeiro princípio deveria abarcar a liberdade fundamental da propriedade privada sobre a terra, de modo que a aplicação do segundo princípio possa e deva justificar uma limitação desse mesmo direito quando isso implicar na redução das desigualdades sociais e econômicas e no aumento da igualdade de oportunidades.

As premissas acima orientam não somente a ideia de que o valor da igualdade humana implica igualdade de bens políticos, sociais e, em alguma medida, de bens econômicos, mas também que, a partir do fundamento da necessidade, as pessoas merecem certos bens independentemente de seus traços de caráter ou de qualquer coisa que tenham feito.

A garantia da propriedade presume-se algo valioso, uma liberdade substantiva, que contribui para que os cidadãos desenvolvam suas capacidades, efetivamente criando condições materiais para a persecução de seus planos de vida. 
A propriedade constitui uma dessas liberdades básicas, bem inerente à dignidade de todo ser humano. Por isso, em determinado grau e amplitude invioláveis e indisponíveis, deve ser garantida a todos, independentemente do plano de vida de cada um.

\section{Referências}

ARISTÓTELES. Ética a Nicômacos. Tradução Mário da Gama Kury. 3. ed. Brasília: Editora Universidade de Brasília, 1999.

\section{BENATTI, José. Direito de propriedade e proteção ambiental}

no Brasil: apropriação e uso dos recursos naturais no imóvel rural. 2003. 344 p. Tese (Doutorado) - Programa de Pós-Graduação em Desenvolvimento Sustentável do Trópico Úmido (PPGDSTU) Universidade Federal do Pará, Núcleo de Altos Estudos Amazônicos, Belém, 2003.

BOBBIO, Norberto; MATTEUCCI, Nicola; PASQUINO, Gianfranco. Dicionário de política. 13. ed. Brasília: UnB, 2007.

BRITO FILHO. José Cláudio Monteiro de. Ações Afirmativas. 3. ed. São Paulo: LTr, 2014.

CALAZANS, Paulo Murillo. Dworkin deixa inestimável legado para a teoria do Direito. Revista Consultor Jurídico, 19 de fevereiro de 2013. Disponível em: http://www.conjur.com.br/2013-fev-19/paulo-calazansdworkin-deixa-inestimavel-legado-teoria-direito. Acesso em: 24 fev. 2017.

CARDIM, Carlos Henrique. Apresentação. In: RAWLS, John. O liberalismo político. Tradução Dinah de Abreu Azevedo. 2. ed. São Paulo: Ática, 2000. p. 5-11.

CITTADINO, Gisele. Pluralismo, direito e justiça distributiva: elementos de filosofia constitucional contemporânea. 3. ed. Rio de Janeiro: Lumen Juris, 2004.

FLEISCHACKER, Samuel. Uma breve história da justiça distributiva. Tradução de Álvaro de Vita. São Paulo: Martins Fontes, 2006. 
HARARI, Yuval Noah. Sapiens: uma breve história da humanidade. 1. ed. Porto Alegre: L\&PM EDITORES, 2018.

LENZ, Maria Heloisa. A teoria da renda da terra em Adam Smith. Ensaios FEE, Porto Alegre, FEE, v. 14, n. 1, p. 144-178, 1993.

PIKETTY, Thomas. O capital no século XXI. Tradução Monica Baumgarten de Bolle. Rio de Janeiro: Intrínseca, 2014.

PIPES, Richard. Propriedade e liberdade. Tradução de Luiz Guilherme B. Chaves e Carlos Humberto Pimentel Duarte da Fonseca. Rio de Janeiro: Record, 2001.

RAMOS, André de Carvalho. Teoria geral dos direitos humanos na ordem internacional. Rio de Janeiro: Renovar, 2005.

RAWLS, John. A Theory of Justice. Revised Edition. Cambridge; Massachusetts: The Belknap Press of Harvard University Press, 1999.

RAWLS, John. Uma teoria da justiça. Tradução Almiro Pisetta e Lenita M. R. Esteves. São Paulo: Martins Fontes, 1997. (2. Tiragem 2000).

RAWLS, John. Uma teoria da justiça. 3. ed. Tradução Jussara Simões. São Paulo: Martins Fontes, 2008.

RAWLS, John. Justiça como equidade: uma reformulação. Organizado por Erin Kelly. Tradução Claudia Berliner. Revisão técnica da tradução Álvaro De Vita. São Paulo: Martins Fontes, 2003.

RAWLS, John. O liberalismo político. 2. ed. Tradução Dinah de Abreu Azevedo. São Paulo, Ática, 2000.

RICARDO, David. Princípios de economia política e tributação. 2. ed. Tradução de Rolf Kuntz. São Paulo: Abril Cultural, 1979. (Título II. Coleção Os pensadores).

ROSAS, Joao Cardoso. Concepções da justiça. Lisboa: Edições 70, 2011. (Coleção O Saber da Filosofia, n. 41).

SARLET, Ingo Wolfgang et. al. Curso de direito constitucional. 3. ed. São Paulo: RT, 2014. 
SEN, Amartya. A ideia de justiça. Tradução Denise Bottmann, Ricardo Doninelli Mendes. São Paulo: Companhia das Letras, 2011.

SEN, Amartya. Desigualdade reexaminada. 2. ed. Tradução Ricardo Donielli Mendes. Rio de Janeiro: Record, 2008.

SILVA, Leandro Ribeiro da. Propriedade rural. Rio de Janeiro: Lumen Juris, 2008.

VITA, Álvaro de. O liberalismo igualitário: sociedade democrática e justiça internacional. São Paulo: Martins Fontes, 2008.

João Daniel Macedo de Sá é professor permanente do Programa de Pósgraduação em Direito da Universidade Federal do Pará (UFPA). Doutor em Direito pela UFPA .

E-mail: E-mail: jdaniel_sa@yahoo.com

Endereço profissional: Programa de Pós-Graduação em Direito do Instituto de Ciências Jurídicas. Universidade Federal do Pará. Av. Augusto Corrêa, n. 1, ampus Universitário do Guamá. Belém, PA. CEP: 66.075-970. 